\title{
Basic Algorithm for Induction Motors Rotor Faults Pre-Determination
}

\author{
A. Petrov ${ }^{1,2}$, A. Rassõlkin ${ }^{2}$, T. Vaimann ${ }^{2}$, A.Belahcen ${ }^{2,3}$, A. Kallaste ${ }^{2}$, I. Plokhov ${ }^{1}$ \\ ${ }^{I}$ Department of Electrical Drives and Automation Systems, Pskov State University, RUSSIA, Address: Lenin \\ Square, 2, 180000, Pskov, Russia \\ ${ }^{2}$ Department of Electrical Power Engineering and Mechatronics, Tallinn University of Technology, ESTONIA \\ Address: Ehitajate tee 5, 19086 Tallinn, Estonia \\ ${ }^{3}$ Department of Electrical Engineering and Automation, Aalto University, FINLAND, Address: P.O. Box 11000, \\ FI-00076 Aalto, Espoo, Finland
}

\begin{abstract}
Due to importance of squirrel cage induction motor in today's industry, the fault detection on that type of motors has become a highly developed area of interest for researchers. The electrical machine is designed for stable operations with minimum noise and vibrations under the normal conditions. When the fault emerges, some additional distortions appear. The necessity to detect the fault in an early stage, to prevent further damage of the equipment due to fault propagation, is one of the most important features of any condition monitoring or diagnostic techniques for electrical machines nowadays. In this paper possible induction motors faults classified and basic algorithm for rotor faults pre-determination is presented.
\end{abstract}

Keywords: Electric machines, modeling, equivalent circuits, fault diagnosis.

\section{INTRODUCTION}

The relatively mature ac induction motors (IMs) technology has advanced fast with the progress of power electronics in the last 40 years. A squirrel cage IM has a very simple rotor construction, which increases the reliability and performance of the motor. The IM has been named the workhorse of the industry due to many advantages over other electrical machines. Those advantages include low cost, rugged configuration, versatility, rather small size and capability to reasonably comply with different power grids supply. Moreover, vector control of the IM can allow the motor to behave in the same manner as a separately excited dc motor, which means straight torque-speed characteristics and flexible control. There is no doubt that wide application of the IM is related with failures of the machines.

Because of large number of different faults that can occur in IM, there are several ways of fault classification. Fault classification based on criteria of IM fault sources is given in Table 1.

Most rotating machine failures occur due to bearing faults and winding faults. Estimated probabilities of occurrence of faults are [1], [2]:

1) Bearing faults $-40 \%$;

2) Stator winding faults $-38 \%$;

3) Rotor faults $-10 \%$;

4) Complex of other faults $-12 \%$.

The next weak spot of the electrical machine is the rotor, the only rotating part in the IM. Main rotor faults are rotor eccentricity; breakage of rotor bars; breakage of end-rings; rotor bow; others failures after rotor damage.

Table 1.

IM fault classification

\begin{tabular}{|c|c|c|}
\hline $\begin{array}{l}\text { Sources of } \\
\text { IM Faults }\end{array}$ & Fault Type & Faults \\
\hline \multirow[t]{2}{*}{ Internal } & Mechanical & $\begin{array}{l}\text { - Eccentricity; } \\
\text { - Rotor strikes; } \\
\text { - Bearing faults; } \\
\text { - Coil and lamination } \\
\text { movement. }\end{array}$ \\
\hline & Electrical & $\begin{array}{l}\text { - Dielectric failures; } \\
\text { - Magnetic circle faults; } \\
\text { - Rotor bars cracks. }\end{array}$ \\
\hline \multirow{3}{*}{ External } & Mechanical & $\begin{array}{l}\text { - Pulsation of load; } \\
\text { - Overload; } \\
\text { - Poor mounting. }\end{array}$ \\
\hline & Electrical & $\begin{array}{l}\text {-Voltage fluctuation; } \\
\text {-Unbalanced voltage; } \\
\text { - Transient voltage. }\end{array}$ \\
\hline & Environmental & $\begin{array}{l}\text { - Temperature; } \\
\text { - Humidity; } \\
\text { - Cleanness }\end{array}$ \\
\hline
\end{tabular}

By employing condition monitoring and fault identification methods the electrical machine failure can be detected at an early stage, which in hand, will prevent the unexpected downtime as a result of accidents, reduce repair costs and increase motor lifespan [3].

\section{II.IM ROTOR CONDITION MONITORING TECHNIQUES}

Condition monitoring techniques for rotor fault detection can broadly be classified as follows [4], [5]:

ISSN 1691-5402

(C) Rezekne Academy of Technologies, Rezekne 2017 http://dx.doi.org/10.17770/etr2017vol3.2526 
- Motor circuit analysis;

- Electromagnetic field monitoring;

- Air-gap torque;

- Stator current;

- Induced voltage;

- Surge testing;

- Instantaneous power;

- Instantaneous angular speed;

- Vibration;

- Acoustic emission.

Some of the methods, like motor circuit analysis require the machine to be taken off-line, which causes additional service and interrupts the manufacturing process.

Methods that use voltage and current measurements offer several advantages over off-line test procedures or techniques that require special sensors to be mounted on the motor [6], [7]. At the same time, the stator current methods are sensitive to motor electrical faults [8].

A lot of research work has been published on diagnosis of vibration of the electrical machines [1], [9]-[12]. Studies show that the vibration method is most sensitive in case of detection of bearing faults [8].

Several studies [6], [1], [13]-[16] have been conducted to acoustic studies and noise generated by the vibration of machine parts. It should be mentioned that audible noise measurements are more complex compared to vibration measurements [14].

The main sources of the noise in IM could be classified in three parts [17], [18] mechanical, aerodynamic and electromagnetic. The main source of mechanical noise generation is the same as vibration source - bearings [9], [10] and rotor unbalance (eccentricity) [16]. The sources of aerodynamic noise in IM are the fans, rotor wings or cooling ducts [17]. The magnetic stress wave acts in radial directions on the stator and rotor active surfaces causing the electromagnetic noise [17]. Several acoustic monitoring methods are presented nowadays: frequency analysis [19]; partial discharge acoustic measurements [15], speckle noise reduction [11].

\section{BASIC ALGORITHM FOR FAULTS PRE- DETERMINATION}

For a large number of diagnostic methods dismantling and disconnection of IM or installation of sensors around the IM perimeter or inside the IM itself is needed. In such case, preliminary examination of IM must be performed. Detection of basic fault signs during preliminary examination is a sufficient reason for continuing with complex and detailed fault determination procedure.

Serious problems in IM rotor can be determined without the use of special equipment and techniques. For example, a bending of rotor bar, which might progress with the bar intruding the air-gap, will cause sharp decreasing of machine speed, or even a jamming of the rotor. Other signs of major problems in IM rotor are excessive heating of the machine and extraneous sounds such as hammering, crackling or gritting.

Rotor faults lead to appearance of higher harmonics of currents and magnetomotive force (MMF), which in hand causes the unbalance of radial force, appearance of additional vibration components and acoustic noise. Thus, increased motor noise and vibration can be considered as signs of IM fault.

Since any fault in electric motor leads to the reducing of its performance, deterioration of static and dynamic characteristics and parameters comparing to rated ones can be a reliable indication of failure occurred in the motor [20]. for the mentioned parameters could be for instance, increased duration of transient processes of induction motor, decreased motor's efficiency and motor power factor, increased values of currents in the motor windings etc.

Motor Current Signature Analysis (MCSA) can also be used for IM fault pre-determination. In the stage of motor preliminary examination, the determination of frequencies present in current spectrum, that are characteristic for cases of squirrel cage faults and rotor eccentricity, would be sufficient. These frequencies can be obtained as:

$$
\begin{gathered}
f_{c b r f}=f_{s}\left[n \frac{(1-s)}{P} \pm s\right] \\
f_{c e}=f_{s}\left[\left(n R_{s} \pm O_{r e}\right) \frac{(1-s)}{P} \pm O_{s m h}\right]
\end{gathered}
$$

where $f_{c b r f}$ - components generated by broken rotor faults; $f_{s}$ - supply frequency, $s$ - per-unit slip; $n=1,2,3 \ldots-$ integral values, $P$ - number of pole pairs; $f_{c e}$ - components associated with eccentricity; $R_{s}$ - number of rotor slots; $O_{r e}$ - rotating eccentricity order; $O_{s m h}-$ stator MMF harmonic order.

It should be noticed, that these frequency components cannot be treated as exact signs of occurrence of motor faults as these frequencies can be detected in the spectrum of even healthy motors due to unavoidable manufacturing symmetries and misalignment etc. Therefore, this sign should be considered only in complex with the others [2].

Based on foregoing, basic pre-determination algorithm is:

1) Motor examination for the presence of obvious signs of IM rotor faults;

2) Motor examination for increased motor noise and vibration;

3) Comparing static and dynamic IM parameters and characteristics with rated ones, identification of differences;

4) Basic current spectrum analysis for the presence of broken rotor faults and eccentricity frequency components. 
After identification of one of these signs, one of the complex and detailed methods of faults determination can be used.

\section{SMARTPHONES}

In present day smartphones have changed our habits and demeanor. Variety of available models and extensions of mobile phones have been used in different ways. Smartphone apps estrange the use of a mobile phone only for calls and bring many different applications, like information collecting and exchange, web services, remote control of devices, locating and traction of objects, etc. Some studies [21], [22] show opportunities for teaching and learning contexts. Special attention is put to use smartphone sensors in different applications [22][24]. Moreover, some of the smartphone based applications [25], [26] are used for medical purposes.

Studies shows [8] that most bearing fault related components could be easily identified in acoustic spectra. That means that it can be easily applied in portable solution as smartphone application for mechanical noise detection [27]. Nowadays, the acoustic analysis is more attractive in bearing fault detection, but there are ongoing investigations to use the smartphones for detection of other machine faults.

Noise measurements are more complex compared to vibration measurements. The advantage of noise monitoring over vibration monitoring is that the former can detect the growth of subsurface cracks, whereas the latter can detect defects only when they appear on the surface [10]. Condition based monitoring technique of the electrical machines is very attractive in bearing faults detection. It has been applied for rotor faults detection by researchers [4], [28] and is used by industries [11], [29] for avoiding sudden machine failure. Some researchers [16], [17] studied the effects of rotor eccentricity on the acoustic emission spectrum from an induction machine.

Broken rotor bars of squirrel-cage induction machines have been the subject of interest in numerous scientific studies. As the given fault is one of the more usual types of failures, condition monitoring to predict the possible fault and detection of broken bars can be considered an important issue in the field of induction machine diagnostics.

Noise produced by an electrical machine can provide the information about the electromagnetic forces as well as. The human ear is most sensitive to sound in the frequency range from $1 \mathrm{kHz}$ to $5 \mathrm{kHz}$, while the sensitivity drops at higher and lower frequencies [14]. Experimental results show that noise produced by the electrical machine is mostly low frequency noise. Analysis of experimental data [28] shows that bearing faults are found in the frequency range from $50 \mathrm{~Hz}$ to $200 \mathrm{~Hz}$ in acoustic signature. It is also important to note that the energy released by neighboring components in the vibrational frequency range (up to $50 \mathrm{kHz}$ ), which often masks the vibrational energy released from a defective rolling element bearing, do not affect the acoustic emission signal released in the very high frequency range [10]. That means the microphone, that records the noise, picks up all the sound signals in its sound field, which means measurement location should be carefully chosen to provide full range of the noise frequencies.

The distribution of the sound power versus frequency is needed for identifying the noisegeneration mechanism. Studies show that noise spectrum depends on the position where the noise has been measured. There are three imaginary measuring surfaces recommended by ISO 3744:2010: hemispherical measurement surface, rectangular parallelepiped surface and conformal surface [14]. Other factors that may influence the noise measurements are size of source [15], source operating conditions [28], surroundings [27], etc.

Microphones in today's smartphones are capable of recording audio signals with frequencies up to $48 \mathrm{kHz}$ [30]. Thereby, there is an opportunity of spectrum audio analysis of faults in the IM, which audible noise is recorded on smartphone from different directions. Due to the advantages of such fault diagnostic method, which are the mobility of recording device and simplicity of organization, it is possible to use this method for IM fault predetermination, along with MCSA diagnostic method.

\section{V.CONCLUSION}

It is important to detect the electrical machine fault in an early stage, to prevent further damage of the equipment due to fault propagation, is one of the main features of any condition monitoring or diagnostic techniques.

The proposed algorithm of detection the basic symptoms of IM rotor faults can be used as algorithm for IM rotor faults pre-determination. The results of such pre-determination procedure can be a sufficient reason for the dismantling of IM and faults determination using desired diagnostic method.

The proposed method of using smartphone for spectrum audio analysis can be used for IM fault predetermination. In future, the research of correctness of the method and the possibility of its implementation will be carried out.

Moreover, our research [31] shows the necessity of posing and solving inverse problems in the diagnostic procedures of electric machines. This is essential in order to achieve better and more precise results in the condition monitoring of the machines due to the growing complexity of the machine setups, which challenges the traditional electric machine diagnosis methods. 


\section{ACKNOWLEDGMENT}

This research has been supported by the Estonian Research Council grants PUT (PUT1260) and PUTJD (PUTJD134), also by European Regional Development Fund under Mobilitas Pluss program returning researcher grant (MOBTP13).

\section{REFERENCES}

[1] M. A. A. Elmaleeh, N. Saad, N. Ahmed, and M. Awan, "Online fault detection \& diagnosis of rotating machines using acoustic emission monitoring techniques," in 2007 International Conference on Intelligent and Advanced Systems, 2007, pp. 897-900.

[2] P. S. Bhowmik, P. S. Bhowmik, S. Pradhan, and M. Prakash, "Fault Diagnostic and Monitoring Methods of Induction Motor: A Review."

[3] L. G. Sidel'nikov and D. O. Afanas'ev, "Control Methods Review of Induction Motors Technical State During Operation", Perm National Research Polytechnic University Gazette," Jpurnal Perm Natl. Res. Polytech. Univ. (In Russ., no. 7, pp. 127-137, 2013.

[4] M. R. Mehrjou, N. Mariun, M. Hamiruce Marhaban, and N. Misron, "Rotor fault condition monitoring techniques for squirrel-cage induction machine-A review," Mech. Syst. Signal Process., vol. 25, no. 8, pp. 2827-2848, Nov. 2011.

[5] S. Nandi, H. A. Toliyat, and X. Li, "Condition Monitoring and Fault Diagnosis of Electrical Motors-A Review," IEEE Trans. Energy Convers., vol. 20, no. 4, pp. 719-729, Dec. 2005.

[6] J. Sottile, F. C. Trutt, and J. L. Kohler, "Experimental investigation of on-line methods for incipient fault detection [in induction motors]," in Conference Record of the 2000 IEEE Industry Applications Conference. Thirty-Fifth IAS Annual Meeting and World Conference on Industrial Applications of Electrical Energy (Cat. No.00CH37129), 2000, vol. 4, pp. 2682-2687.

[7] A. Kallaste, A. Belahcen, A. Kilk, and T. Vaimann, "Analysis of the eccentricity in a low-speed slotless permanent-magnet wind generator," in 2012 Electric Power Quality and Supply Reliability, 2012, pp. 1-6.

[8] W. Li, "Detection of Induction Motor Faults: A Comparison of Stator Current, Vibration and Acoustic Methods," J. Vib. Control, vol. 12, no. 2, pp. 165-188, Feb. 2006.

[9] D. S. Shah and V. N. Patel, "A Review of Dynamic Modeling and Fault Identifications Methods for Rolling Element Bearing," Procedia Technol., vol. 14, pp. 447-456, 2014.

[10] N. Tandon and A. Choudhury, "A review of vibration and acoustic measurement methods for the detection of defects in rolling element bearings," Tribol. Int., vol. 32, no. 8, pp. 469-480, Aug. 1999.

[11] B. Torcianti, C. Cristalli, and J. Vass, "Non-Contact Measurement for Mechanical Fault detection in Production Line," in 2007 IEEE International Symposium on Diagnostics for Electric Machines, Power Electronics and Drives, 2007, pp. 297-301.

[12] J. Sobra, T. Vaimann, and A. Belahcen, "Mechanical vibration analysis of induction machine under dynamic rotor eccentricity," in 2016 17th International Scientific Conference on Electric Power Engineering (EPE), 2016, pp. $1-4$.

[13] A. Gaylard, "Acoustic evaluation of faults in electrical machines," in Seventh International Conference on Electrical Machines and Drives, 1995, vol. 1995, pp. 147150.

[14] S. P. Verma and W. Li, "Measurement of Vibrations and Radiated Acoustic Noise of Electrical Machines," Electrical Machines and Systems, 2003. ICEMS 2003. Sixth International Conference on, vol. 2. pp. 861-866 vol.2, 2003.

[15] Xiaoqin Ma, Weisheng Lu, Xiangtian Chun, and Hengkun Xie, "Acoustical technology applications in large high voltage motors," in Proceedings of 2001 International Symposium on Electrical Insulating Materials (ISEIM 2001). 2001 Asian Conference on Electrical Insulating Diagnosis (ACEID 2001). 33rd Symposium on Electrical and Electronic Insulating Materials and Applications in System, 2001, pp. 737-740

[16] A. J. Ellison and S. J. Yang, "Effects of rotor eccentricity on acoustic noise from induction machines," Proc. Inst. Electr. Eng., vol. 118, no. 1, p. 174, 1971.

[17] M. Janda, O. Vitek, and M. Skalka, "Noise diagnostic of induction machine," in The XIX International Conference on Electrical Machines - ICEM 2010, 2010, pp. 1-4.

[18] S. P. Verma, "Noise and vibrations of electrical machines and drives; their production and means of reduction," in Proceedings of International Conference on Power Electronics, Drives and Energy Systems for Industrial Growth, 1996, vol. 2, pp. 1031-1037.

[19] W. Doorsamy and W. A. Cronje, "A study on Bayesian spectrum estimation based diagnostics in electrical rotating machines," in 2014 IEEE International Conference on Industrial Technology (ICIT), 2014, pp. 636-640.

[20] A. Rassolkin et al., "Adjusted electrical equivalent circuit model of induction motor with broken rotor bars," in 2016 Electric Power Quality and Supply Reliability (PQ), 2016, pp. 213-218.

[21] D. May and P. Ossenberg, "Fit for science a course for teaching to organize, perform and present scientific work in engineering with mobile devices," in 2015 IEEE Global Engineering Education Conference (EDUCON), 2015, pp. $176-183$.

[22] M. A. Bochicchio, M. Zappatore, and A. Longo, "Using Mobile Crowd Sensing to teach technology and entrepreneurship in high schools: An experience from Southern Italy," in 2015 IEEE Global Engineering Education Conference (EDUCON), 2015, pp. 948-953.

[23] J. Lim, S. J. Lee, G. Tewolde, and J. Kwon, "Ultrasonicsensor deployment strategies and use of smartphone sensors for mobile robot navigation in indoor environment," in IEEE International Conference on Electro/Information Technology, 2014, pp. 593-598.

[24] A. Anjum and M. U. Ilyas, "Activity recognition using smartphone sensors," in 2013 IEEE 10th Consumer Communications and Networking Conference (CCNC), 2013, pp. 914-919.

[25] X. Xu et al., "Advances in Smartphone-Based Point-of-Care Diagnostics," Proc. IEEE, vol. 103, no. 2, pp. 236-247, Feb. 2015.

[26] J. Lee, J. Jung, J. Lee, and Y. T. Kim, “Acute myocardial infarction detection system using ECG signal and cardiac marker detection," in IEEE SENSORS 2014 Proceedings, 2014, pp. 2255-2257.

[27] N. K. Verma, S. Sarkar, S. Dixit, R. K. Sevakula, and A. Salour, "Android app for intelligent CBM," in 2013 IEEE International Symposium on Industrial Electronics, 2013, pp. 1-6.

[28] W. Li, "Detection of Induction Motor Faults: A Comparison of Stator Current, Vibration and Acoustic Methods," J. Vib. Control, vol. 12, no. 2, pp. 165-188, Feb. 2006.

[29] M. A. A. Elmaleeh, N. Saad, and M. Awan, "Condition monitoring of industrial process plant using acoustic emission techniques," in 2010 International Conference on Intelligent and Advanced Systems, 2010, pp. 1-6.

[30] P. Rzeszucinski, M. Orman, C. T. Pinto, A. Tkaczyk, and M. Sulowicz, "A signal processing approach to bearing fault detection with the use of a mobile phone," in 2015 IEEE 10th International Symposium on Diagnostics for Electrical Machines, Power Electronics and Drives (SDEMPED), 2015, pp. 310-315.

[31] T. Vaimann, A. Belahcen, and A. Kallaste, "Necessity for implementation of inverse problem theory in electric machine fault diagnosis," in 2015 IEEE 10th International Symposium on Diagnostics for Electrical Machines, Power Electronics and Drives (SDEMPED), 2015, pp. 380-385. 
Environment. Technology. Resources, Rezekne, Latvia Proceedings of the $11^{\text {th }}$ International Scientific and Practical Conference. Volume III, 254-257 